Received: 2020/08/24, Revised: 2020/09/14,

Accepted: 2020/09/14, Published: 2020/09/30

(๑2020 Sang-Seok Nam and Hun-Young Park.; Licence Physical Activity and Nutrition. This is an open access article distributed under the terms of the creative commons attribution license (http://creativecommons.org/licenses/ by(2.0), which permits unrestricted use, distribution, and reproduction in any medium, provided the orginal work is properly cited.

${ }^{*}$ Corresponding author : Hun-Young Park

Department of Sports Medicine and Science of Graduated School / Physical Activity and Performance Institute, Konkuk University, Seoul, Korea

Phone: +82-2-2049-6035

E-mail: parkhy1980@konkuk.ac.kr

@2020 The Korean Society for Exercise Nutrition

[Purpose] This study was performed to investigate the acid-base and ion balance at rest and after exercise in healthy males under normoxia, moderate hypoxia, and severe hypoxia.

[Methods] Ten healthy Korean males completed three different trials on different days, comprising exercise under normoxia $\left(\mathrm{F}_{\mathrm{i}} \mathrm{O}_{2}=20.9 \%, \mathrm{~N}\right.$ trial), moderate hypoxia $\left(\mathrm{F}_{\mathrm{i}} \mathrm{O}_{2}=16.5 \%\right.$, $\mathrm{MH}$ trial), and severe hypoxia $\left(\mathrm{F}_{2} \mathrm{O}_{2}=12.8 \%, \mathrm{SH}\right.$ trial $)$. They undertook endurance exercise for $30 \mathrm{~min}$ on a cycle ergometer at the same relative exercise intensity equivalent to $80 \%$ maximal heart rate under all conditions. Capillary blood samples were obtained to determine acid-base and ion balance at rest and after exercise.

[Results] Exercise-induced blood lactate elevations were significantly increased as hypoxic conditions became more severe; $\mathrm{SH}>\mathrm{MH}>\mathrm{N}$ trials $(P=0.003)$.

After exercise, blood glucose levels were significantly higher in the $\mathrm{SH}$ trial than in the $\mathrm{N}$ and $\mathrm{MH}$ trials $(P=$ 0.001 ). Capillary oxygen saturation $\left(\mathrm{S}_{\mathrm{C}} \mathrm{O}_{2}\right)$ levels were significantly lowered as hypoxic conditions became more severe; $\mathrm{SH}>\mathrm{MH}>\mathrm{N}$ trials $(P<0.001)$. The $\mathrm{pH}$ levels were significantly lower in the $\mathrm{MH}$ trial than that in the $\mathrm{N}$ trial $(P=0.010)$. Moreover, $\mathrm{H}_{\mathrm{C}} \mathrm{O}_{3}$ - levels were significantly lower in the $\mathrm{SH}$ trial than in the $\mathrm{N}$ trial, with significant interaction $(P=0.003)$. There were no significant differences in blood $\mathrm{Na}^{+}, \mathrm{K}^{+}$, and $\mathrm{Ca}^{2+}$ levels between the trials.

[Conclusion] $\mathrm{MH}$ and $\mathrm{SH}$ trials induced greater differences in glucose, lactate, $\mathrm{S}_{\mathrm{c}} \mathrm{O}_{2}, \mathrm{pH}$, and $\mathrm{HCO}_{3}$ - levels in capillary blood compared to the $\mathrm{N}$ trial. Additionally, lactate, $\mathrm{S}_{\mathrm{C}} \mathrm{O}_{2}$, and $\mathrm{HCO}_{3}$ - levels showed greater changes in the $\mathrm{SH}$ trial than in the $\mathrm{MH}$ trial. However, there were no significant differences in $\mathrm{Na}^{+}, \mathrm{K}^{+}$, and $\mathrm{Ca}^{2+}$ levels in $\mathrm{MH}$ and $\mathrm{SH}$ trials compared to the $\mathrm{N}$ trial.

[Key words] acute hypoxia, metabolic stress, capillary blood, potassium kinetics, submaximal exercise, blood lactate, blood glucose

\section{Effects of endurance exercise under hypoxia on acid-base and ion balance in healthy males}

\author{
Sang-Seok Nam ${ }^{1}$ / Hun-Young Park ${ }^{2,3^{*}}$ \\ 1. Taekwondo Research Institute of Kukkiwon, Seoul, Korea \\ 2. Department of Sports Medicine and Science of Graduated School, Konkuk University, Seoul, Korea \\ 3. Physical Activity and Performance Institute (PAPI), Konkuk University, Seoul, Korea
}

\section{INTRODUCTION}

Exercise training in hypobaric hypoxia has been widely accepted as a useful method of enhancing the endurance performance of athletes, and a considerable amount of experimental evidence has accumulated regarding the efficacy of this training method. ${ }^{1-4}$ Under hypobaric hypoxia, atmospheric pressure decreases; thus, the partial pressure of oxygen in the atmosphere decreases so that oxygen available in the same volume of air decreases, thereby inducing hypoxia., ${ }^{5,6}$ Exercise under hypoxia induces lower arterial oxygen saturation and red blood cell deformability, whereas carbohydrate substrate mobilization and blood lactate levels during exercise are augmented. ${ }^{5,-9}$ In general, these physiological responses during exercise under hypoxia improve athletic performance and promote peripheral adaptation in the muscles. ${ }^{10}$ However, the mechanism for these adaptive phenomena is not yet fully understood.

Hypoxia makes the energy supply more dependent on the glycolytic system during exercise by reducing the systemic oxygen supply, and these changes lead to metabolic acidosis through increased ATP synthesis by anaerobic metabolic processes, an increase of hydrogen ions, and a decrease in $\mathrm{pH} .{ }^{11,12}$ Exercise-induced accumulation of lactate and hydrogen ions reduces exercise performance. ${ }^{12,13}$ Once hydrogen ions are produced in the muscles through exercise, they are buffered primarily by the bicarbonate $\left(\mathrm{HCO}_{3}\right.$ ) buffering system in the bloodstream. ${ }^{10} \mathrm{Hy}-$ poxia rapidly increases minute ventilation and induces increased carbon dioxide removal, which relates to respiratory alkalosis. ${ }^{12,14}$ Exercise in a hypoxic environment causes complex changes in the acid-base balance by $\mathrm{HCO}_{3}$ - and is simultaneously affected in terms of both metabolic acidosis induced by exercise and respiratory alkalosis induced by hypoxia. ${ }^{14}$ Therefore, the exercise-induced kinetics of blood $\mathrm{HCO}_{3}$ - under hypoxia reflect the homeostasis of the acid-base balance in blood. ${ }^{10}$

In addition to the acid-base balance, the ion balance is critical to muscle excitation, contraction, metabolism, and thus for muscle function during exercise. ${ }^{15}$ The accumulation of extracellular potassium ions $\left(\mathrm{K}^{+}\right)$reduces the excitability of active muscles and lowers exercise tolerance. ${ }^{16,17}$ 
Increased muscle $\mathrm{Na}^{+}-\mathrm{K}^{+}$pump concentration via exercise training is usually associated with a reduced rise in plasma $\mathrm{K}^{+}$during exercise. ${ }^{17}$ Exercise under hypoxia is more dependent on anaerobic metabolism, with a concomitant increase in $\mathrm{K}^{+}$during exercise in the blood, than exercise under normoxia. ${ }^{5,7}$ These metabolic responses during exercise under hypoxia lead to acid-base responses, such as a concomitant release of $\mathrm{K}^{+}$from the cell into extracellular fluid by increasing the opening of the muscular ATP-sensitive $\mathrm{K}^{+}$ channels. ${ }^{18,19}$ In other words, exercise under hypoxia may augment exercise-induced alterations of acid-base and ion balances compared with exercise under normoxia. Lühker et al. ${ }^{14}$ examined the differences in acid-base and ion balance during exercise under severe hypoxia $\left(12 \% \mathrm{~F}_{\mathrm{i}} \mathrm{O}_{2}\right.$, equivalent to an altitude of $4500 \mathrm{~m}$ ) and normoxia. They found a significant difference in $\mathrm{pH}$ and blood lactate levels during a $200 \mathrm{~W}$ cycle ergometer exercise between hypoxia and normoxia. However, Sumi et al. ${ }^{10}$ compared the effects of acidbase and ion balance in response to high-intensity interval exercise under moderate hypoxia $\left(14.5 \% \mathrm{~F}_{\mathrm{i}} \mathrm{O}_{2}\right.$, equivalent to an altitude of $3000 \mathrm{~m}$ ) in endurance athletes. They reported that exercise under hypoxia did not elicit a decrease in blood $\mathrm{pH}$ or increase in $\mathrm{K}^{+}$levels compared to an equivalent level of exercise under normoxia. The difference between these studies is the result of the difference in hypoxic conditions and exercise intensity.

Therefore, it is important to examine the differences in acid-base and ion balance during exercise under various hypoxic conditions. The purpose of this study was to evaluate the acid-base and ion balance at rest and after exercise in healthy males under normoxia, moderate hypoxia, and severe hypoxia. We hypothesized that exercise under moderate and severe hypoxia would induce greater exerciseinduced alterations of acid-base and ion balances compared with exercise under normoxia.

\section{METHODS}

\section{Participants}

Ten healthy Korean males participated in this study. The age, height, and body weight [mean \pm standard deviation (SD)] of the participants were $29.6 \pm 5.8$ years, 176.2 $\pm 3.6 \mathrm{~cm}$, and $62.9 \pm 3.2 \mathrm{~kg}$, respectively. The participants were nonsmokers and had no history of musculoskeletal, cardiovascular, or pulmonary diseases. In addition, they had not participated in any exercise program under hypobaric hypoxia or normobaric hypoxia in the previous six months. The participants provided their signed consent after sufficient explanation of the experiment and possible adverse effects. This study was approved by the Institutional Review Board of KyungHee University (KHSIRB 2015-020) in Korea. All procedures followed were in accordance with the ethical standards of the committee for responsible experimentation on humans and the Declaration of Helsinki.

\section{Study design}

The participants visited the laboratory four times during the experimental period. During the first visit, all participants underwent fasting for more than $8 \mathrm{~h}$, and after stabilization, height and body composition were measured in the morning. On the second, third, and fourth occasions, participants performed experimental trials in randomized order under normoxia $\left(20.9 \% \mathrm{~F}_{\mathrm{i}} \mathrm{O}_{2}\right.$, equivalent to sea level, $\mathrm{N}$ trial), moderate hypoxia $\left(16.5 \% \mathrm{~F}_{\mathrm{i}} \mathrm{O}_{2}\right.$, equivalent to an altitude of $2000 \mathrm{~m}, \mathrm{MH}$ trial), and severe hypoxia $\left(12.8 \% \mathrm{~F}_{\mathrm{i}} \mathrm{O}_{2}\right.$, equivalent to an altitude of 4000 $\mathrm{m}, \mathrm{SH}$ trial). All participants completed endurance exercise for $30 \mathrm{~min}$ on a cycle ergometer (Aerobike 75XLII; Konami Corporation, Tokyo, Japan) at the same relative exercise intensity equivalent to $80 \%$ maximal heart rate (HRmax) using Miyashita formula (male $=209-0.69 \times$ age). ${ }^{20}$ At rest and after exercise, capillary blood samples were obtained and analyzed. All experiments were performed in a $6.5 \times 7.5 \times 3 \mathrm{~m}$ environmental chamber (Submersible Systems, Huntington Beach, CA, USA) for all conditions. Various hypoxic conditions were simulated by introducing nitrogen into the environmental chamber using a nitrogen generator (Separation \& Filter Energy Technology Cooperation, Siheung, Korea) with the capacity to simulate hypoxic conditions for altitudes of up to $9.7 \% \mathrm{O}_{2}$, equivalent to an altitude of $6000 \mathrm{~m}$. The temperature and humidity within the environmental chamber were maintained at $20 \pm 2{ }^{\circ} \mathrm{C}$ and $60 \% \pm 2 \%$, respectively, for all conditions. The three trials were spaced at least one week apart and performed at the same time of day, and the order of the trials was randomized.

\section{Measurements}

Body composition. Body composition (i.e., height, body weight, fat-free mass, and $\%$ body fat) was measured after fasting for more than $8 \mathrm{~h}$ using bioelectrical impedance analysis equipment (Inbody 770, Inbody, Korea).

Blood variables. After $8 \mathrm{~h}$ of fasting, blood variables were measured at rest and immediately after exercise for $30 \mathrm{~min}$. Blood glucose, lactate, capillary oxygen saturation $\left(\mathrm{S}_{\mathrm{C}} \mathrm{O}_{2}\right), \mathrm{pH}, \mathrm{HCO}_{3^{-}}$, sodium $\left(\mathrm{Na}^{+}\right), \mathrm{K}^{+}$, and calcium $\left(\mathrm{Ca}^{2+}\right)$ levels were measured using a blood gas analyzer (Gem Premier 3000, Radiometer, Denmark). For the acid-base and ion-balance measurements, blood samples were collected using the fingertip method in the capillary vessel. The acid-base and ion response results of the capillary blood were similar to those of the arterial blood, indicating the reliability of the results and that this is an easier sampling method compared to arterial blood sampling..$^{21,22}$ Additionally, blood samples were collected with the fingertip method after heating the capillary to $43^{\circ} \mathrm{C}$, using an electric pad and massage for the influx of arterial blood, based on previous studies regarding heating the blood collection region and using stimulants, such as irritant cream, glyceryl trinitrate paste, and nicotinate paste. ${ }^{12}$ After blood sampling, the responses of the acid-base and ion balance were evaluated within $10 \mathrm{~s}$ of closing the 
front and back of the collection tube to prevent the reaction of the blood sample with gases in the atmosphere.

\section{Statistical analysis}

Means and standard deviations were calculated for all dependent variables. Normality of distribution of all outcome variables was verified using the Shapiro-Wilk test. Two-way analysis of variance (ANOVA) with repeated measures was used to assess the presence of interactions (trial $\times$ time) and main effects (trial or time). When ANOVA revealed a significant interaction or main effect, the least significant difference test was performed as a post hoc analysis to identify the differences. $P<0.05$ were considered statistically significant in all tests. All analyses were performed using the Statistical Package for the Social Sciences (SPSS) version 24.0.

\section{RESULTS}

\section{Blood variables}

\section{Metabolites}

Figure 1 shows the changes in blood glucose and lactate levels. Blood glucose levels decreased significantly with exercise in all trials (main effect for time, $P<0.001$ ). After exercise, blood glucose levels were significantly higher in the $\mathrm{SH}$ trial than in the $\mathrm{N}$ and $\mathrm{MH}$ trials (main effect for trial, $P=0.001$ ). The blood lactate levels increased significantly with exercise in all trials (main effect for time, $P<0.001)$. Exercise-induced blood lactate level elevations were significantly increased as the hypoxic conditions became more severe; $\mathrm{SH}>\mathrm{MH}>\mathrm{N}$ trials (interaction, $P=0.001$; main effect for trial, $P=0.003$ ).

Blood $\mathrm{S}_{\mathrm{C}} \mathrm{O}_{2}, \mathrm{pH}$, and $\mathrm{HCO}_{3-}$

Figure 2 illustrates the changes in blood $\mathrm{S}_{\mathrm{C}} \mathrm{O}_{2}, \mathrm{pH}$, and $\mathrm{HCO}_{3}$ - levels. The $\mathrm{S}_{\mathrm{C}} \mathrm{O}_{2}$ levels decreased significantly with exercise in the $\mathrm{SH}$ trials (main effect for time, $P=$ 0.027). After exercise, $\mathrm{S}_{\mathrm{C}} \mathrm{O}_{2}$ levels were significantly reduced as the hypoxic condition became more severe; $\mathrm{SH}$ $>\mathrm{MH}>\mathrm{N}$ trials (main effect for trial, $P<0.001$ ). The $\mathrm{pH}$ levels decreased significantly with exercise in all trials (main effect for time, $P=0.010$ ). After exercise, $\mathrm{pH}$ levels were significantly lower in the $\mathrm{MH}$ trial than in the $\mathrm{N}$ trial (main effect for trial, $P=0.010$ ). The $\mathrm{HCO}_{3}$ - levels decreased significantly with exercise in all trials (main effect for time, $P<0.001$ ), and there was a significant interaction between time and trial $(P=0.003)$.

\section{Blood $\mathrm{Na}^{+}, \mathrm{K}^{+}$, and $\mathrm{Ca}^{2+}$}

Changes in blood $\mathrm{Na}^{+}, \mathrm{K}^{+}$, and $\mathrm{Ca}^{2+}$ levels with exercise for all trials are shown in Figure 3. The $\mathrm{Na}^{+}$and $\mathrm{K}^{+}$ levels increased significantly after exercise in all trials (main effect for time, $P<0.001$ ), whereas there were no significant differences between trials at any time point. The $\mathrm{Ca}^{2+}$ levels were significantly lower in the SH trial than in the $\mathrm{N}$ trial (main effect for trial, $P=0.019$ ).

\section{DISCUSSION}

According to our hypothesis, exercise under moderate and severe hypoxia would induce greater differences in glucose, lactate, $\mathrm{S}_{\mathrm{C}} \mathrm{O}_{2}, \mathrm{pH}$, and $\mathrm{HCO}_{3}$ - levels in capillary blood compared with exercise under normoxia. In addition, lactate, $\mathrm{S}_{\mathrm{C}} \mathrm{O}_{2}$, and $\mathrm{HCO}_{3}$ - levels showed greater changes in the $\mathrm{SH}$ trial than the $\mathrm{MH}$ trial. However, there were no great differences in $\mathrm{Na}^{+}, \mathrm{K}^{+}$, and $\mathrm{Ca}^{2+}$ levels in $\mathrm{MH}$ and $\mathrm{SH}$ trials compared with the $\mathrm{N}$ trial.

Hypoxia decreases the systemic oxygen-carrying capacity and peripheral oxygen-utilizing capacity, making it more dependent on glycolysis; these changes induce an increase in blood glucose levels, blood lactate levels, and respiratory exchange ratio during exercise. ${ }^{8,23}$ Exposure to and exercise under hypoxia induce a decrease in oxygen
(A)

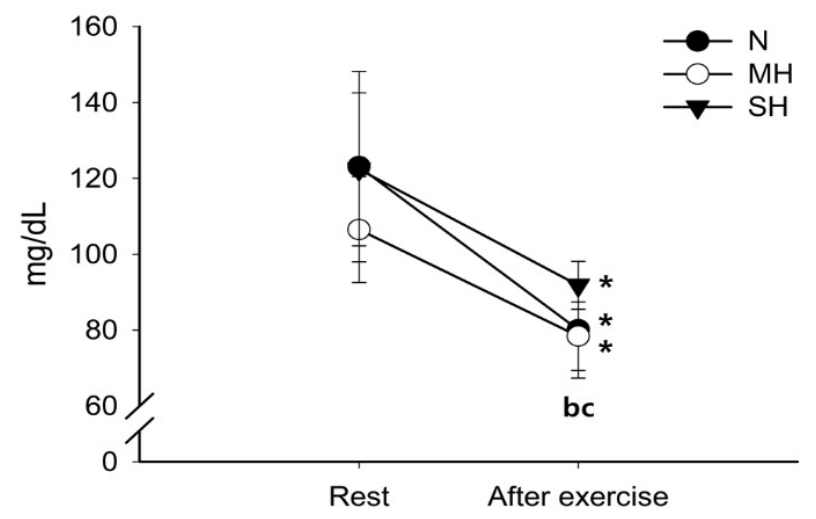

(B)

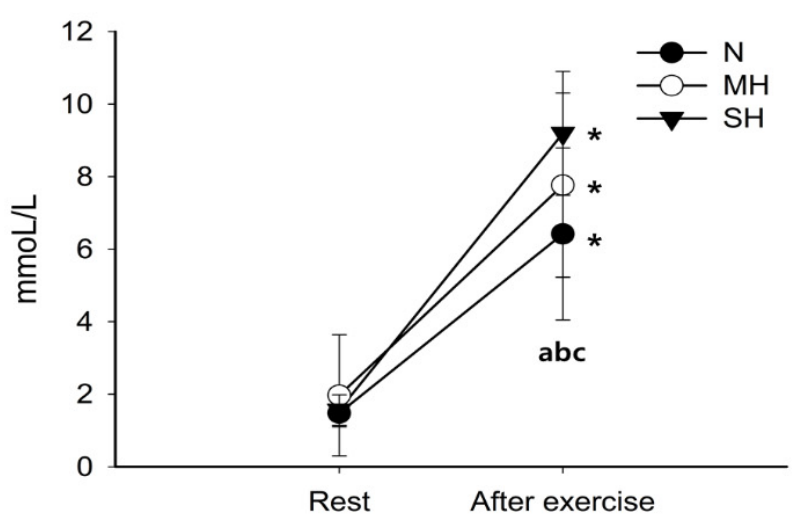

Figure 1. Changes in blood glucose (A) and lactate (B) concentrations. Values are mean \pm standard deviation (SD). * significant difference compared with pre-exercise. ${ }^{\text {a }}$ Significant difference between normoxia $(\mathrm{N})$ and moderate hypoxia $(\mathrm{MH})$ trials. ${ }^{\mathrm{b}}$ Significant difference between $\mathrm{N}$ and severe hypoxia (SH) trials. 'Significant difference between MH and SH trials. 
(A)

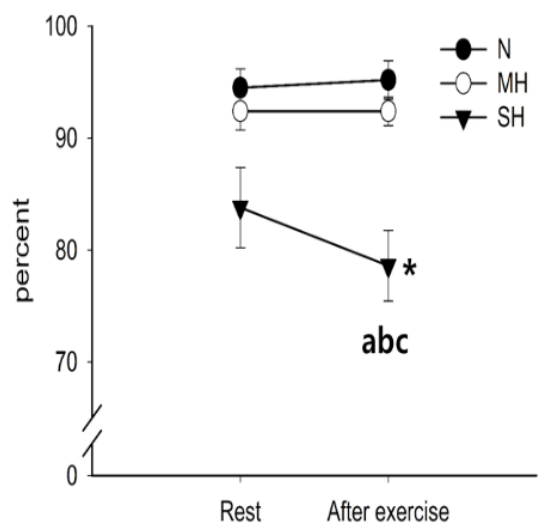

(B)

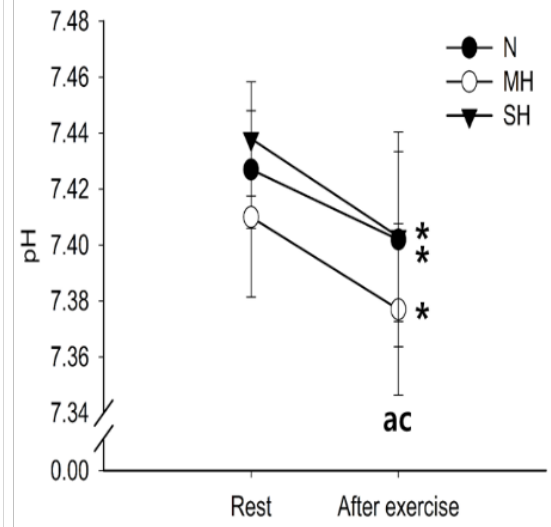

(C)

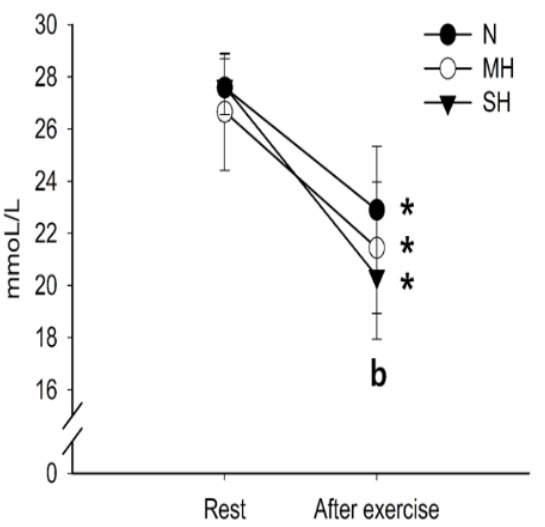

Figure 2. Changes in $\mathrm{S}_{\mathrm{C}} \mathrm{O}_{2}(\mathrm{~A}), \mathrm{pH}(\mathrm{B})$, and $\mathrm{HCO}_{3}$ (C) levels. Values are mean \pm standard deviation (SD). *Significant difference compared with pre-exercise. ${ }^{a}$ Significant difference between normoxia $(\mathrm{N})$ and moderate hypoxia $(\mathrm{MH})$ trials. 'Significant difference between $\mathrm{N}$ and severe hypoxia (SH) trials. ${ }^{\circ}$ Significant difference between $\mathrm{MH}$ and $\mathrm{SH}$ trials.

(A)

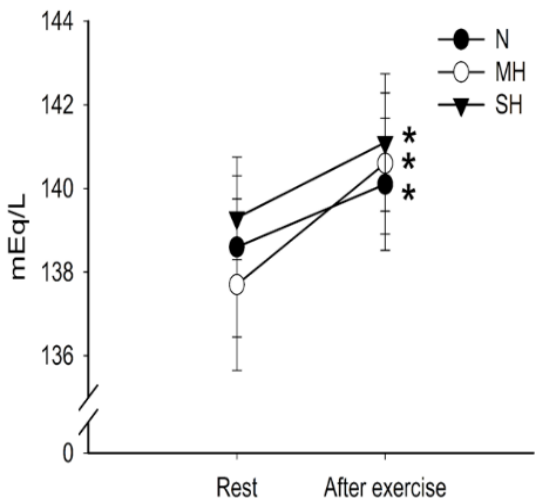

(B)

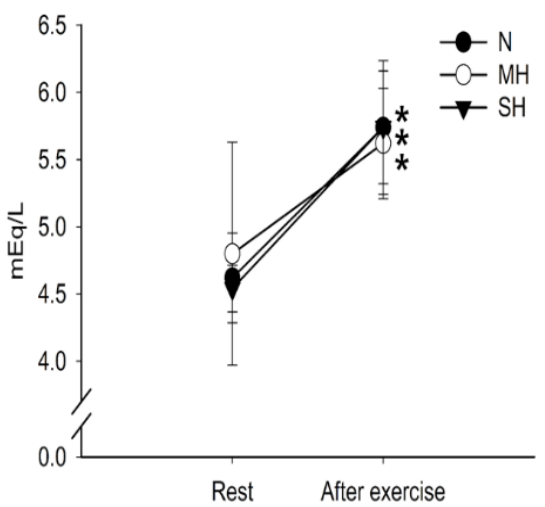

(C)

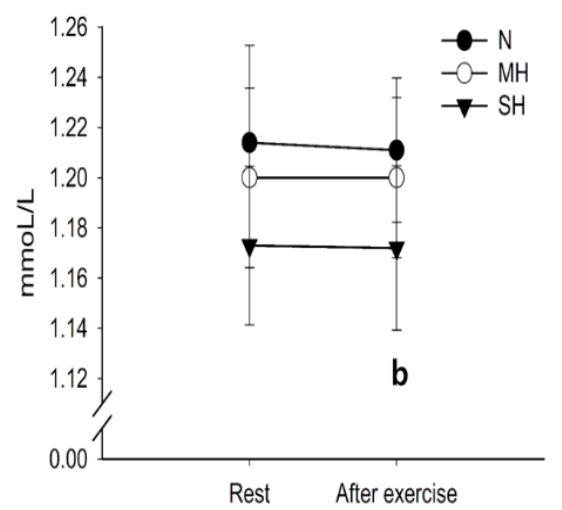

Figure 3. Changes in $\mathrm{Na}^{+}(\mathrm{A}), \mathrm{K}^{+}(\mathrm{B})$, and $\mathrm{Ca}^{2+}(\mathrm{C})$ concentrations. Values are mean \pm standard deviation (SD). * Significant difference compared with pre-exercise. ${ }^{a}$ Significant difference between normoxia $(\mathrm{N})$ and moderate hypoxia $(\mathrm{MH})$ trials. ${ }^{b}$ Significant difference between $\mathrm{N}$ and severe hypoxia (SH) trials. ${ }^{\circ}$ Significant difference between $\mathrm{MH}$ and $\mathrm{SH}$ trials.

saturation in the arterial blood, resulting in an augmented energy supply from the glycolytic system, increasing the blood lactate level and production of hydrogen ions $\left(\mathrm{H}^{+}\right) .{ }^{9,10,24}$ The augmented metabolic stress stimulates the opening of ATP-sensitive $\mathrm{K}^{+}$channels in the muscle, subsequently increasing $\mathrm{K}^{+}$outflow to the extracellular fluid in the active muscle. ${ }^{24,25}$ Additionally, proton production is further increased during exercise under hypoxia; protons are then released into the bloodstream, and the blood is buffered by the $\mathrm{HCO}_{3}$ - buffer system. ${ }^{14,15}$ Moreover, the acid-base response by the $\mathrm{HCO}_{3}$ - buffer system is caused by an increase in ventilation during exercise. ${ }^{12}$ Lühker et al. ${ }^{14}$ investigated the differences in acid-base and ion balance during exercise under severe hypoxia $\left(12 \% \mathrm{~F}_{\mathrm{i}} \mathrm{O}_{2}\right.$, equivalent to an altitude of $4500 \mathrm{~m}$ ) and normoxia, and hypoxia showed a significant decrease in $\mathrm{pH}$ and increase in blood lactate levels during a $200 \mathrm{~W}$ cycle ergometer exercise compared to normoxia. In our study, SH showed a greater blood glucose level after exercise compared to the $\mathrm{MH}$ and $\mathrm{N}$ trials, and exercise-induced blood lactate level elevations were significantly increased as the hypoxic conditions became more severe; $\mathrm{SH}>\mathrm{MH}>\mathrm{N}$ trials. In addition, the $\mathrm{MH}$ and $\mathrm{SH}$ trials showed a lower $\mathrm{S}_{\mathrm{C}} \mathrm{O}_{2}, \mathrm{pH}$, and $\mathrm{HCO}_{3}$ - than the $\mathrm{N}$ trial after exercise. These findings were consistent with those of Sumi et al. ${ }^{10}$ and Woorons et al. ${ }^{26}$

Regarding the ion balance, our initial hypothesis was that the MH and SH trials would augment the exerciseinduced blood $\mathrm{K}^{+}$elevation compared with the $\mathrm{N}$ trial. Because lower $\mathrm{S}_{\mathrm{C}} \mathrm{O}_{2}$ and $\mathrm{pH}$ increases the opening of $\mathrm{K}_{\text {ATP }}$ channels, we believed that $\mathrm{K}^{+}$would efflux from the working muscle into the bloodstream. ${ }^{24,27}$ The increased 
accumulation of extracellular $\mathrm{K}^{+}$during exercise under hypoxia is manifested by the enhanced release of $\mathrm{K}^{+}$in the working muscle and decreased reuptake of $\mathrm{K}^{+}$during exercise. ${ }^{24}$ Street et al. ${ }^{18}$ verified that extracellular $\mathrm{K}^{+}$ accumulation and metabolic alkalosis were strongly correlated; their findings seem reasonable, considering the significant increase in $\mathrm{K}^{+}$and $\mathrm{Ca}^{2+}$ induced by exercise in all trials $(\mathrm{SH}, \mathrm{MH}$, and $\mathrm{N}$ ) in our study.

However, our results did not show a significant difference in $\mathrm{K}^{+}$after exercise between $\mathrm{SH}$ and $\mathrm{MH}$ trials and the $\mathrm{N}$ trial. Although the exercise type and intensity differed, results reported by Sumi et al. ${ }^{10}$ and Sumi et al. ${ }^{24}$ regarding ion balance were similar to those of our study. Sumi et al. ${ }^{10}$ investigated the effects of acid-base and ion balance in response to high-intensity interval exercise under moderate hypoxia $\left(14.5 \% \mathrm{~F}_{\mathrm{i}} \mathrm{O}_{2}\right)$ and normoxia in endurance athletes. They reported that exercise under hypoxia did not elicit a decrease in blood $\mathrm{pH}$ and increase in $\mathrm{K}^{+}$levels compared with an equivalent level of exercise under normoxia. The difference between these previous studies is due to the difference in hypoxic conditions and exercise intensity. Additionally, Sumi et al..$^{24}$ investigated the acid-base balance and $\mathrm{K}^{+}$kinetics in response to exercise (relative exercise intensity) under moderate hypoxia $\left(14.5 \% \mathrm{~F}_{\mathrm{i}} \mathrm{O}_{2}\right)$ among endurance athletes (age: $20.7 \pm 0.9$ years, height: $172.5 \pm 2.2 \mathrm{~cm}$, body mass: $61.6 \pm 2.8$ $\mathrm{kg}$ ). They reported that endurance exercise under moderate hypoxia elicited a decline in venous $\mathrm{pH}$; however, it did not induce an increase in blood $\mathrm{K}^{+}$levels compared with normoxia. These two previous studies suggest that exercise (high-intensity interval exercise and endurance exercise) under moderate hypoxia cause greater metabolic stress and similar exercise-induced elevation of blood $\mathrm{K}^{+}$ compared with the same exercise under normoxia, despite lower exercise absolute load. These findings were confirmed in our study examining the effects of exercise under moderate and severe hypoxia on the acid-base and ion balance in healthy males compared with exercise under normoxia. In other words, our study confirmed that severe hypoxic conditions induced a greater metabolic response during exercise, without affecting the ion balance, such as $\mathrm{K}^{+}, \mathrm{Na}^{+}$, and $\mathrm{Ca}^{2+}$ kinetics, during exercise compared to normoxia.

In conclusion, the $\mathrm{MH}$ and $\mathrm{SH}$ trials induced greater differences in glucose, lactate, $\mathrm{S}_{\mathrm{C}} \mathrm{O}_{2}, \mathrm{pH}$, and $\mathrm{HCO}_{3}$ levels in capillary blood compared to the $\mathrm{N}$ trial. Additionally, lactate, $\mathrm{S}_{\mathrm{C}} \mathrm{O}_{2}$, and $\mathrm{HCO}_{3}$ - levels showed greater changes in the $\mathrm{SH}$ than in the $\mathrm{MH}$ trial. However, there were no significant differences in $\mathrm{Na}^{+}, \mathrm{K}^{+}$, and $\mathrm{Ca}^{2+}$ levels in $\mathrm{MH}$ and $\mathrm{SH}$ trials compared with the $\mathrm{N}$ trial.

\section{ACKNOWLEDGEMENTS}

This work was supported by the Ministry of Education of the Republic of Korea and the National Research Foundation of Korea (NRF-2019S1A5A2A03034583).

\section{REFERENCES}

1. Park HY, Hwang H, Park J, Lee S, Lim K. The effects of altitude/hypoxic training on oxygen delivery capacity of the blood and aerobic exercise capacity in elite athletes - a metaanalysis. J Exerc Nutrition Biochem. 2016;20:15-22.

2. Park HY, Lim K. Effects of hypoxic training versus normoxic training on exercise performance in competitive swimmers. Med Sci Sports Exerc. 2017;16:480-8.

3. Park HY, Lim K. Intermittent hypoxic training for 6 weeks in $3000 \mathrm{~m}$ hypobaric hypoxia conditions enhances exercise economy and aerobic exercise performance in moderately trained swimmers. Biol Sport. 2018;35:49-56.

4. Brocherie F, Girard O, Faiss R, Millet GP. Effects of repeatedsprint training in hypoxia on sea-level performance: A metaanalysis. Sports Med. 2017;47:1651-60.

5. Moon HW, Shin SH, Lee CH, Park HY, Sunoo S, Nam SS. Effects of various acute hypoxic conditions on the hemorheological response during exercise and recovery. Clin Hemorheol Microcirc. 2016;63:451-60.

6. Sinex JA, Chapman RF. Hypoxic training methods for improving endurance exercise performance. J Sport Health Sci. 2015;4:325-32.

7. Moon HW, Sunoo S, Park HY, Lee DJ, Nam SS. Effects of various acute hypoxic conditions on metabolic parameters and cardiac function during exercise and recovery. SpringerPlus. 2016;5:1294.

8. Katayama K, Goto K, Ishida K, Ogita F. Substrate utilization during exercise and recovery at moderate altitude. Metabolism. 2010;59:959-66.

9. Sumi D, Kojima C, Goto K. Impact of endurance exercise in hypoxia on muscle damage, inflammatory and performance responses. J Strength Cond Res. 2018;32:1053-62.

10. Sumi D, Kojima C, Kasai N, Goto K. The effects of endurance exercise in hypoxia on acid-base balance and potassium kinetics: a randomized crossover design in male endurance athletes. Sports Medicine - Open 2018;4:45.

11. Juel C, Lundby C, Sander M, Calbet JAL, van Hall G. Human skeletal muscle and erythrocyte proteins involved in acidbase homeostasis: adaptations to chronic hypoxia. J Physiol. 2003;548:639-48.

12. Park HY, Sunoo S, Nam SS. The effects of 4 weeks fixed and mixed intermittent hypoxic training $(\mathrm{IHT})$ on respiratory metabolic and acid-base response of capillary blood during submaximal bicycle exercise in male elite Taekwondo players. $J$ Exerc Nutrition Biochem. 2016;20:35-43.

13. Mollard $\mathrm{P}$, Woorons $\mathrm{X}$, Letournel M, Lamberto $\mathrm{C}$, Favret $\mathrm{F}$, Pichon A, Beaudry M, Richalet JP. Determinant factors of the decrease in aerobic performance in moderate acute hypoxia in women endurance athletes. Respir Physiol Neurobiol. 2007;159:178-86.

14. Lühker O, Berger MM, Pohlmann A, Hotz L, Gruhlke T, Hochreiter $M$. Changes in acid-base and ion balance during exercise in normoxia and normobaric hypoxia. Eur J Appl Physiol. 2017;117:2251-61.

15. Sejersted OM, Sjøgaard G. Dynamics and consequences of potassium shifts $n$ skeletal muscle and heart during exercise. Physiol Rev. 2000;80:1411-81. 
16. Allen $\mathrm{DG}$, Lamb GD, Westerblad $\mathrm{H}$. Skeletal muscle fatigue: cellular echanisms. Physiol Rev. 2008;88:287-332.

17. McKenna MJ, Harmer AR, Fraser SF, Li JL. Effects of training on potassium, calcium and hydrogen ion regulation in skeletal muscle and blood during exercise. Acta Physiol Scand. 1996;156:335-46

18. Street D, Nielsen JJ, Bangsbo J, Juel C. Metabolic alkalosis reduces exercise induced acidosis and potassium accumulation in human skeletal muscle interstitium. J Physiol. 2005;566:481-9.

19. Cairns SP, Lindinger MI. Do multiple ionic interactions contribute to skeletal muscle fatigue? J Physiol. 2008;586:403954.

20. Miyashita M, Mutoh Y, Yoshika Y, Sadamoto T. Effects of physical training. Med Sci Sports Exerc. 1985;1:3-5.

21. Dar K, Williams T, Aitken R, Woods KL, Fletcher S. Arterial versus capillary sampling for analysing blood gas pressures. BMJ. 1995;310:24-5.

22. Zavorsky GS, Cao J, Mayo NE, Gabbay R, Murias JM. Arterial versus capillary blood gases: A meta-analysis. Respi Physiol Neurobio. 2007;155:268-79.

23. Morishima T, Mori A, Sasaki H, Goto K. Impact of exercise and moderate hypoxia on glycemic regulation and substrate oxidation pattern. PLoS One 2014;9:e10862

24. Sumi $\mathrm{D}$, Kasai $\mathrm{N}$, Ito $\mathrm{H}$, Goto $\mathrm{K}$. The effects of endurance exercise in hypoxia on acid-base, potassium kinetics, and exogenous glucose oxidation. Front Physiol. 2019;10:504.

25. Niess AM, Fehrenbach E, Strobel G, Roecker K, Schneider EM, Buergler J., Fuss S, Lehmann R, Northoff H, Dickhuth $\mathrm{HH}$. Evaluation of stress responses to interval training at low and moderate altitudes. Med Sci Sports Exerc. 2003;35;263-9.

26. Woorons $X$, Mollard $P$, Lamberto $C$, Letournel M, Richalet JP. Effects of acute hypoxia on maximal exercise in trained and sedentary women. Med Sci Sports Exerc. 2005;37:147-54.

27. Nielsen HB, Hein L, Svendsen LB, Secher NH, Quistorff, B. Bicarbonate attenuates intracellular acidosis. Acta Anaesthesiol Scand. 2002;46:579-84. 